\title{
A Study to Evaluate Role of Intraperitoneal Saline Wash for Shoulder Tip Pain Reduction after Laparoscopic Cholecystectomy
}

Rajneesh $\mathrm{K}^{1 *}$, Ankur $\mathrm{H}^{2}$, Subhash $\mathbf{G}^{2}$ and Ramandeep Singh $\mathbf{W}^{2}$

${ }^{1}$ Department of Surgery, Punjab Institute of Medical Sciences [PIMS], Jalandhar, Punjab, India

${ }^{2}$ Punjab Institute of Medical Sciences [PIMS], Jalandhar, India

\begin{abstract}
Background: Shoulder tip pain after laparoscopic procedures is common leading to patient's distress, delayed discharge.

Objective: To evaluate simple and effective intervention to reduce incidence of shoulder tip pain after laparoscopic cholecystectomy.

Setting: Tertiary care medical college.

Materials and methods: Eighty patients of cholelithiasis were included in study and aim of study will compare incidence of shoulder tip pain in two groups of 40 each. Group A (Study group) received thorough intraperitoneal saline wash and in Group B (Control group), no saline wash will be done. We intend to thoroughly wash the peritoneal cavity after the removing all blood clots and debris with $0.9 \%$ normal saline till clear fluid is seen in the cavity. Postoperative pain was assessed by visual analogue scale at fixed time intervals.
\end{abstract}

Results: When VAS score was analysed in two groups. Study group add less score as compared to control group, though statistically insignificant $(P>0.05)$, reduction of incidence of shoulder tip pain was found within 24 hours post-operatively. This shows that incidence of shoulder tip pain after laparoscopic cholecystectomy was reduced by intraperitoneal wash. Additional analgesic requirement was significantly less in study group $(P=0.005)$ at 1 hour after surgery, highly significant $(p=0.000)$ up to 6 hours and again significant at $6-12$ hours post-operatively $(p=0.005)$. Analgesic requirement though reduced in study group at $12-24$ hours but not statistically significant $(p=0.338)$.

Conclusion: Intraperitoneal saline wash was effective in decreasing shoulder tip pain after laparoscopic cholecystectomy.

Keywords: Shoulder tip pain; Laparoscopic cholecystectomy; Intraperitoneal saline; VAS score

\section{Introduction}

Laparoscopic cholecystectomy is a gold standard procedure with worldwide acceptance. First laparoscopic cholecystectomy was performed way back in 1987 by Phillip Mauret and later established by Dubois and Perissat in 1990 [1,2]. It is associated with lower mortality and shorter hospitalization, smaller incision, early return to normal activity and less post-operative pain. However laparoscopic procedures are associated with shoulder pain and cause lot of discomfort to the patient. The incidence of shoulder pain varies from $35-80 \%$. Severity of pain ranges from mild to severe [3,4]. Intraperitoneal inflation with $\mathrm{CO}_{2}$ causes stretching of abdominal tissue, causes traumatic small blood vessel tear, nerve traction and release of inflammatory mediators causing perioperative pain $[5,6]$. Pain may be visceral, somatic, upper abdomen, lower abdomen or in shoulder [7].

As far shoulder pain in laparoscopic procedure though precise reason is unclear, but leading hypothesis is that $\mathrm{CO}_{2}$ introduced in abdomen cause phrenic nerve irritation causing referred pain to C4 segment [8]. Prolonged presence of shoulder tip pain suggests excitation of phrenic nerve [9]. Reason attributed to actual cause of pain due to carbon dioxide is cellular death caused by combination of temperature change from the gas at $21^{\circ} \mathrm{C}$ and drying effect of gas in abdomen [10]. It may be transient or persistent for up to 3 days after laparoscopic cholecystectomy [11]. This increases patient's morbidity and analgesic requirement. Number of studies to reduce shoulder pain such as low pressure $\mathrm{CO}_{2}$ is preferred for abdominal wall lift $[12,13]$. Decreased pressure may have delay surgery and jeopardise safety and the benefit/risk should be accessed at individual basis [14]. Pre-emptive anti-inflammatory medication [15]. Pre-emptive diaphragmatic local anaesthesia irrigation and post-operative sub-diaphragmatic suction
[16-18]. All these methods and studies got conflicting results. Patient complaining of pain in shoulder mainly by respiratory movements, coughing and movements during first postoperative hours may prolong hospital stay, postoperative morbidity and increase hospital cost [19]. Often drugs and opiates reduce postoperative pain after laparoscopic cholecystectomy but their adverse effects including nausea, vomiting may delay hospital discharge. So different postoperative pain management protocols can reduce the opiates administration in such cases [20,21]. Tsimoyiannis et al. [22] showed beneficial effect of intraperitoneal saline wash with suction and sub-hepatic drain to reduce incidence of postoperative shoulder pain. As $\mathrm{CO}_{2}$ retention is a key factor in abdominal and shoulder tip pain in laparoscopy, removing or washing out residual $\mathrm{CO}_{2}$ might help to reduce the severity of pain in both shoulder and upper abdomen .There are different methodologies to reduce this pain in addition to NSAIDS/Opioids, like port site infiltration of local anaesthesia, suprascapular blocks or piroxicam patch [23]. Other pre- emptive steps to reduce post laparoscopic cholecystectomy shoulder tip pain are intraperitoneal saline wash, low pressure pneumoperitoneum [12,24]. Removal of insufflated gas or

*Corresponding author: Rajneesh K, Department of Surgery, Punjab Institute of Medical Sciences [PIMS], Jalandhar, Punjab 144006, India, Tel: 09814052513 E-mail: drrajneeshkumar@ymail.com

Received September 20, 2017; Accepted October 10, 2017; Published October 15, 2017

Citation: Rajneesh K, Ankur H, Subhash G, Singh RW (2017) A Study to Evaluate Role of Intraperitoneal Saline Wash for Shoulder Tip Pain Reduction after Laparoscopic Cholecystectomy. Surgery Curr Res 7: 301. doi: 10.4172/21611076.1000301

Copyright: (c 2017 Rajneesh K, et al. This is an open-access article distributed under the terms of the Creative Commons Attribution License, which permits unrestricted use, distribution, and reproduction in any medium, provided the original author and source are credited. 
use of gas drains [25]. Use of $\mathrm{N}_{2} \mathrm{O}$, Helium, Argon, heated gas in place of $\mathrm{CO}_{2}$ [26]. Bupivacaine infusion under right hemi-diaphragm [27]. There are no standard guidelines to reduce shoulder tip pain. Aim of our study is to compare intraperitoneal saline wash to reduce shoulder tip pain and control group.

\section{Materials and Methods}

In the present study conducted on 80 patients of ASA 1 and 2, undergoing laparoscopic cholecystectomy for symptomatic cholelithiasis were randomly divided into two groups of 40 each.

All patients were operated under general anaesthesia with preoxygenation for few minutes with $100 \%$ oxygen. Induction done with injection glycopyrolate $(0.1 \mathrm{mg}) \mathrm{i} / \mathrm{v}$, injection fentanyl $2 \mu \mathrm{g} / \mathrm{kg} /$ iv, propafol $(1-1.5 \mathrm{mg} / \mathrm{kg}) \mathrm{i} / \mathrm{v}$, endotracheal intubation with succinyl choline with facilitation, intermittent positive pressure ventilation was done with Bain's circuit through Boyle's anaesthesia apparatus. Maintenance was done with oxygen, $\mathrm{N}_{2} \mathrm{O}$, isoflurane, inj atracurium and inj fentanyl. Residual effect of atracurium reserved with neostigmine and glycopyrrolate. Standard four port laparoscopic cholecystectomy done by experienced laparoscopic surgeons. At the end of surgery study group received through intraperitoneal saline wash after removing all blood clots and debris with $0.9 \%$ normal saline till clear fluid is seen in the cavity. Control group did not receive any thorough wash except for removing blood clot and debris with suction and clots with stone/ sponge holding forceps.

Before surgery, informed consent was taken from patient explaining the visual analogue scale. The patient marked a vertical line on a horizontal line marked 0 on left side and 10 on extreme right.

- 0 marked indicates no pain.

- 1-3 mark indicates mild pain.

- 4-7 mark indicates moderate pain.

- 8-10 mark indicates severe pain.

- Inj. Diclofenac was given to patient with VAS score of 1-3.

- Inj. Tramadol was given to patient with VAS score 4-7 or to those patients who demanded stronger analgesics.

Inj. Butradol was given in some extreme cases with VAS score 8-10

Level of shoulder tip pain was accessed by this 10 point VAS score at 1, 6, 12, 24 hour interval and analgesic requirement in first 24 hours after the surgery. Data was analysed and results were reported as mean \pm standard deviation. The $\mathrm{p}$-value of less than 0.05 was taken as statistically significant difference between the two groups.

\section{Results}

The two groups were matched and there was no significant difference regarding age, sex and duration of surgery.

VAS Score at 1, 6, 12 and 24 hours after surgery were assessed in both groups. Number of patients having mild, moderate and severe, shoulder pain was higher in control group in all assessed hours after surgery compare to those in the study group, which was relieved by injection diclofenac, tramadol, butradol were given depending upon severity of pain. Though statistically not significant, reduction of incidence of shoulder tip pain was found at 24 hour post operatively. This shows that incidence of post-operative shoulder tip pain was reduced by intraperitoneal saline wash as compared to no wash (Table 1 and 2).

\begin{tabular}{|c|c|c|c|}
\hline Parameter & Control Group & Study Group & P Value \\
\hline Age, Year & $18-58(35.0 \pm 12.08)$ & $\begin{array}{c}23-73(37.3 \pm \\
13.12)\end{array}$ & 0.527 \\
\hline Male: Female & $08: 32$ & $10: 30$ & \\
\hline $\begin{array}{c}\text { Duration of Surgery, } \\
\text { Hours }\end{array}$ & $\begin{array}{c}25-110(66.25 \pm \\
25.89)\end{array}$ & $\begin{array}{c}35-120(74.25 \pm \\
22.20)\end{array}$ & 0.944 \\
\hline
\end{tabular}

Table 1: Demographic parameter and duration of surgery in study.

Table 3 shows that $95 \%$ of group A required no pain killer during 1 hour after surgery as compared to $65 \%$ in group B. Only $5 \%$ required pain killer NSAID in first hour whereas $25 \%$ required painkiller in group B.

The above Table 4 shows $40 \%$ patients in group A required no injection of painkiller as compared to $0 \%$ in group B at 6 hours. $55 \%$ patients in group A requires one injection of NSAID (inj. diclofenac) as compared to $47.5 \%$ in group B. $5 \%$ in group A required second injection of opioid (Inj.Tramadol) as compared to $47.5 \%$ in group B. No patient required third injection of opioid (Inj. Butradol) in group A as compared to $5 \%$ in group B. When Chi-Square test was applied to, compare the number of injections in two groups. It was found that highly statistically significant reduction was made in the number of injections used in two groups. Table 5 shows those $72.5 \%$ patients in group A and $52.5 \%$ in group B required no analgesia between 6-12 hours. Patient in group A only required 1 injection of painkiller as compared to $35 \%$ in group B. Only $2.5 \%$ patient in group A required 2nd injection as compared to $12.5 \%$ in group B between 6-12 hours. When Chi-Square test was applied to compare the number of injections in two groups, it was found that statistically significant reduction was made. Tables 6 shows that $92.5 \%$ patients in group A and $85 \%$ in group B required no analgesia, only $7.5 \%$ patients in group a required 1 injection of painkiller as compared to $15 \%$ in group B between 1224 hours. When Chi-Square test was applied to compare the number of injections in two groups, it was found that reduction in number of injections was made which was not statistically significant.

First injection given was Diclofenac, second injection if required was Tramadol and third injection given even if pain did not subsided was by Butradol as pain killer.

\section{Discussion}

Shoulder pain after laparoscopic procedures occur in $35 \%$ to $65 \%$ of patients and $\mathrm{CO}_{2}$ is the most frequently used gas for creation of pneumoperitoneum. Use of lowest effective intra-abdominal pressure creating adequate working field should be used. As awareness of the effects of capnoperitoneum and vigilant monitoring in order to maintain physiology, oxygenation and oxygen delivery and potential gas entrapment to surrounding tissues and for vascular space. Shoulder pain results from peritoneal insufflation especially when an exaggerated Trendelenburg position is used [3].

In present era of day care surgery, shoulder tip pain may delay discharge in $10-20 \%$ of patients which is attributed to stretching of subdiaphragmatic fibres of phrenic nerve by increase concavity of diaphragm, which is induced by pneumoperitoneum and the resulting loss of visceral surface tension [22]. Pressure for creation of pneumoperitoneum is usually about $12-16 \mathrm{mmHg}$. $\mathrm{CO}_{2}$ is put into peritoneal cavity through insufflators and flow may vary from 2 liters/ min to 8 liters/min [28].

Delay in discharge due to pain adds to hospital costs. Moreover, carbon dioxide retention with in abdomen irritates phrenic nerve and causing referred pain in $\mathrm{C} 4$ dermatome. Another cause of nerve 


\begin{tabular}{|c|c|c|c|c|c|}
\hline Shoulder Pain Score (Vas) & \multicolumn{3}{|c|}{ Study/ Control } & \multicolumn{2}{c|}{ P Value } \\
\hline Severe (8-10) & $4 / 20$ & $2 / 10$ & 01-Apr & $0 / 2$ & 0.09 \\
\hline Moderate(4-7) & $4 / 10$ & $4 / 8$ & 02-Oct & $1 / 4$ & 0.038 \\
\hline Mild(1-3) & $18 / 10$ & $16 / 20$ & $25 / 20$ & $35 / 30$ & 0.100 \\
\hline No Pain 0 & $14 / 0$ & $18 / 2$ & $12-J u n$ & $4 / 4$ & 0.160 \\
\hline Time After Surgery (Hours) & 1 & 6 & 12 & 24 & \\
\hline
\end{tabular}

Table 2: VAS score at I, 6, 12 and 24 hours.

\begin{tabular}{|c|c|c|c|c|}
\hline Time & No of Injections & Group A & Group B & Total \\
\hline \multirow{2}{*}{1 Hour } & 0 & $38(95 \%)$ & $26(65 \%)$ & $64(80 \%)$ \\
\cline { 2 - 5 } & 1 & $2(5 \%)$ & $14(25 \%)$ & $16(20 \%)$ \\
\hline Total & & $40(100 \%)$ & $40(100 \%)$ & $80(100 \%)$ \\
\hline Pearson Chi -Square & P Value=0.005 & & & Significant \\
\hline
\end{tabular}

Table 3: Analgesic required at 1 hour.

\begin{tabular}{|c|c|c|c|c|}
\hline Time & No Of Injections & Group A & Group B & Total \\
\hline & 0 & $16(40 \%)$ & $0(0 \%)$ & $16(20 \%)$ \\
\cline { 2 - 5 } & 1 & $22(55 \%)$ & $19(47.5 \%)$ & $41(51.25 \%)$ \\
\cline { 2 - 5 } & 2 & $2(5 \%)$ & $19(47.5 \%)$ & $21(26.25 \%)$ \\
\hline \multirow{3}{*}{ 6 Hours } & 3 & $0(0 \%)$ & $2(5 \%)$ & $2(2.5 \%)$ \\
\hline Total & & $40(100 \%)$ & $40(100 \%)$ & $80(100 \%)$ \\
\hline
\end{tabular}

Pearson Chi-Square, $P$ Value $=0.000$, Highly Significant

Table 4: Analgesic required at 6 hours.

\begin{tabular}{|c|c|c|c|c|}
\hline Time & No Of Injections & Group A & Group B & Total \\
\hline \multirow{3}{*}{12 Hours } & 0 & $29(72.5 \%)$ & $21(52.5 \%)$ & $50(62.5 \%)$ \\
\cline { 2 - 5 } & 1 & $10(25 \%)$ & $14(35 \%)$ & $24(30 \%)$ \\
\cline { 2 - 5 } & 2 & $1(2.5 \%)$ & $5(12.5 \%)$ & $6(7.5 \%)$ \\
\hline \multirow{2}{*}{ Total } & & $40(100 \%)$ & $40(100 \%)$ & $80(100 \%)$ \\
\hline
\end{tabular}

Pearson Chi-Square, $\mathrm{P}$ Value $=0.005$, Significant

Table 5: Analgesic requirement at 6-12 hours.

\begin{tabular}{|c|c|c|c|c|}
\hline Time & No of injections & Group A & Group B & Total \\
\hline \multirow{2}{*}{24 Hours } & 0 & $37(92.5 \%)$ & $34(85 \%)$ & $71(88.75 \%)$ \\
\cline { 2 - 5 } & 1 & $3(7.5 \%)$ & $6(15 \%)$ & $9(11.25 \%)$ \\
\hline Total & $40(100 \%)$ & $40(100 \%)$ & $80(100 \%)$ \\
\hline \multicolumn{2}{|l|}{ Pearson chi-square, P Value=0.338, Not Significant } \\
\hline
\end{tabular}

Table 6: Analgesic requirement between 12-24 hours.

irritation is a result of cellular death caused by a combination of temperature change from the gas at $21^{\circ} \mathrm{C}$ and the drying effect of the gas [29]. Hypothermia caused by $\mathrm{CO}_{2}$ cause abdominal and shoulder pain and tachycardia. Thus heating of $\mathrm{CO}_{2}$ gas to $37^{\circ} \mathrm{C}$ during laparoscopy significantly reduce intraoperative hypothermia abdominal and shoulder pain and tachycardia [30,31]. Several other causes have been attributed to shoulder tip pain like peritoneal stretching, diaphragmatic injury, and even shoulder abduction during surgery [32].

Another factor attributed to shoulder pain is due to peritoneal irritation by carbonic acid and due to creation of space between liver and diaphragm [33]. Thus low pressure pneumoperitoneum and removal of insufflated gas or use of gas drains [12,24,25]. Use of $\mathrm{N}_{2} \mathrm{O}$, Helium or Argon in place of $\mathrm{CO}_{2}$ [26] bupivacaine infusion under right hemidiaphragm [27] warm and humified gasless laparoscopy [34]. And in intraperitoneal instillation of normal saline [22,35,36] are some methods that have been studied for reduction of abdominal and shoulder pain after laparoscopic cholecystectomy. For relief of shoulder tip pain, intraperitoneal infusion of normal saline at body temperature until the liver is submerged without fluid suction after deflation of pneumoperitoneum was first reported by Perry and Trambello [37] and then these results were confirmed by Duchene [38] with encouraging results.Tsionoyiannis et al. [22] studies confirmed that saline wash at body temperature reduce post laparoscopy abdominal and shoulder tip pain with or without suctioning out of saline and keeping sub hepatic drains offered no benefit over saline wash for reduction of shoulder tip pain though may offer some benefit for reduction of abdominal pain. Tas B et al. [28] evaluated techniques to reduce shoulder pain after laparoscopic surgery for benign gynaecological diseases, concluded that pulmonary recruitment manoeuvre and intraperitoneal drainage were found to reduce the incidence and severity of shoulder pain. Radke et al. [25] concluded reduction of shoulder pain as well nausea, vomiting after laparoscopic surgery more than half by infusing normal saline post operatively. In our study thorough suctioning of saline was done and significant reduction in pain was obtained. Huang et al. [35] confirmed that intraperitoneal infusion of normal saline can reduce post- operative pain after laparoscopic cholecystectomy. In this study infusion of saline into peritoneum into right hemidiaphragm is done to reduce amount of $\mathrm{CO}_{2}$ between diaphragm and liver. Patient placed in $30^{\circ}$ Trendelenburg position rather than a supine position to eliminate potential gas space between liver and diaphragm. However, total amount of saline infused in each patient was not the same. Post-operative pain score was significantly reduced in experimental group. This study confirm definite role of saline wash for reduction of shoulder tip pain. Tsai et al. [39] directly compared saline wash and pulmonary recruitment manuovre (PRM). They concluded that both PRM and intraperitoneal normal saline infusion (INSI) could effectively reduce pain after laparoscopic surgery but intraperitoneal normal saline infusion might be better for both upper abdominal and shoulder pain. Different studies have revealed that intraperitoneal infusion of saline resulted in a significant reduction in shoulder pain severity compared with nothing. One study which is also a randomised controlled trial agrees with these results that shoulder tip pain induced by $\mathrm{CO}_{2}$ pneumoperitoneum can be safely reduced with a simple procedure as thorough saline wash of peritoneal cavity. Normal saline solution works by dissolution of $\mathrm{CO}_{2}$ gas from abdominal cavity. After thorough removal of blood blood clots, debris and surgical smoke from peritoneal cavity leads to decrease in postoperative pain including shoulder tip pain.

\section{Conclusion}

Our study concludes that intraperitoneal saline wash after laparoscopic cholecystectomy significantly effective in reducing shoulder tip pain in early post-operative period. We recommend use of intraperitoneal saline wash routinely after laparoscopic cholecystectomy which is simple safe procedure, to minimise post-operative abdominal and shoulder tip and analgesic requirement which enhances early mobilization and discharge especially in day care surgery.

\section{Conflict of Interest}

There is no conflict of interest.

\section{References}

1. Dubois F, Icard P, Berthelot G, Levard H (1990) Coelioscopic cholecystectomy. Premilary report of 36 cases. Ann Surg 211: 60-62.

2. Litynski GS (1999) Mouret, Dubois, and Perissat: The laparoscopic breakthrough in Europe (1987-1988). JSLS 3: 163-167.

3. Alexander J (1997) Pain after laparoscopy. Br J Anaesth 79: 369-378

4. Castor CL, Seidel SL, Bushmiaer M (1996) Recovery from laparoscopic cholecystectomy procedures. ARON J 63: 1099-1103.

5. Cunniffe MG, McAnena OJ, Dar MA, Calleary J, Flynn N (1998) A prospective randomized trial of intra operative bupivacaine irrigation for management of shoulder pain following laparoscopy. Am J Surg 176: 258-61. 
Citation: Rajneesh K, Ankur H, Subhash G, Singh RW (2017) A Study to Evaluate Role of Intraperitoneal Saline Wash for Shoulder Tip Pain Reduction after Laparoscopic Cholecystectomy. Surgery Curr Res 7: 301. doi: 10.4172/2161-1076.1000301

6. Schoeffler MJ, Diemunsch GY, Fourgeaud AP (1992) Pain after laparoscopy. Br J Anaesth 20: 337-340.

7. Chu PT, Gin T, Oh TE (1993) Anesthesia for laparoscopic general surgery Anesthesia Analog 21: 163-171.

8. Jackson SA, Laurence AS, Hill JC (1996) Does post laparoscopy pain relate to residual $\mathrm{CO}_{2}$. Anaesthesia 51: 485-7.

9. Sarac AM, Aktan AO, Baykan N, Yegen C, Yalin R (1996) The effect and timing of local anesthesia in laparoscopic cholecystectomy. Surg Laparosc Endosc 6: $362-66$

10. Verhoeven H, Demco L (2000) How can laparoscopy be less painfull. American Association of Gynecological Laparoscopists Conference Nov.

11. Joris J, Cigarini, Legrand M, Jacquet N, DE Groote D, et al. (1992) Metabolic and respiratory changes after cholecystectomy performed via laparotomy or laparoscopy. Brit J Anesth 69: 341- 45.

12. Sarli L, Costi R, Sansebastiano G, Trivelli M, Roncoroni L (2000) Prospective randomized trial of low pressure pneumoperitoneum for reduction of shoulder tip pain following laparoscopy. Br J Surg 87: 1161-5.

13. Berberoglu M, Dilek ON, Ercan F, Kati I, Ozmen M (1998) The effect of CO insufflation rate on the postlaparoscopic shoulder pain. J Laparoendosc Adv Surg Tech A 8: 273-277.

14. Gurusamy KS, Vaughan J, Davidson BR (2014) Low pressure versus standard pressure pneumoperitoneum in laparoscopic cholecystectomy. Cochrane Database Syst Rev 3: CD006930.

15. Phinchantra P, Bunyavehchevin S, Suwajanakorn S, Wisawasukmongchol W (2004) The preemptive analgesic effect of celecoxib for day-case diagnostic laparoscopy. J Med Assoc Thai 87: 283-288

16. Ng A, Swami A, Smith G, Robertson G, Lloyd DM (2004) Is intraperitoneal levobupvicaine with epinephrine useful for analgesia following laparoscopic cholecystectomy? A randomized controlled trial. Eur J Anaesth 21: 653-657.

17. Weber A, Munoz J, Garteiz D, Cueto J (1997) Use of subdiaphragmatic bupivacaine instillation to control post operative pain after laparoscopic surgery. Surg Laparosc Endosc 7: 6-8.

18. Jorgensen JO, Gillies RB, Hunt DR, Caplehorn JR, Lumley T (1995) A simple and effective way to reduce postoperative pain after laparoscopic cholecystectomy. Aust NZ Surg 65: 466-469.

19. Lum Yw, House MG, Hayanga AJ, Michael S (2006) Postcholecystectomy syndrome in the laparoscopic era. J Laparoendosc Adv Surg Tech A 16: 482 485.

20. Gouda ME, Emad NH, Mohamed AE, Morsy K, Saadl S, et al. (2011) Intraincisional vs intraperitoneal infiltration of local anesthetic for controlling early post-laparoscopic cholecystectomy pain. J Minim Access Surg 7: 173177.

21. Bisgaard T, Birthe K, Jacob R, Henrik K (2001) Factors determining convalescence after uncomplicated laparoscopic cholecystectomy. Arch Surg 136: 917-921.

22. Tsimoyiannis EC, Siakas P, Tassis A, Lekkas ET, Tzouru H, et al. (1998)
Intraperitoneal normal saline infusion for post operative pain after laparoscopic cholecystectomy. World J Surg 22: 824-28.

23. Hong JY, Lee IH (2003) Suprascapular nerve block or a piroxicam patch for shoulder tip pain after day care laparoscopic surgery. Eur J Anaesth 20: 234-8.

24. Esmat ME, Elsebae MMA, Nasr MMA, Elsebaie SB (2006) Combined low pressure pneumoperitonium and intraperitoneal infusion of normal saline for reducing shoulder tip pain following laparoscopic cholecystectomy. World Journal of Surgery 30: 1969-73.

25. Radke OC, Phelps P, Cakmakkaya OS, Apfel CC (2008) A simple clinica maneuver to reduce laparoscopy induced shoulder pain. A randomized clinical trial. Obstetrics and Gynaecology 111: 1155-60.

26. Douglas EO, Larry Demco (2006) How can laparoscopy be less painful? ObGyn Compensation Survey.

27. Gharaibeh KI, Al-Jaberi TM (2000) Bupivacaine instillation into gallbladder bed after laparoscopic cholecystectomy: does it decrease shouldr pain. J Laparoendosc Adv Surg Tech A 10: 137-141

28. Tas B, Donatsky AM, Gogenur I (2013) Techniques to reduce shoulder pain after laparoscopic surgery for benign gynaecological disease A systematic review. Gynecological Surgery 10: 169-175.

29. https://www.isge.org/

30. Korell M, Schmaus F, Strowitzki T, Scheeweiss SG, Hepp H (1996) Pain intensity following laparoscopy. Surg Laparosc Endosc 6: 375-379.

31. Semm K, Arp WD, Trappe M, Kube D (1994) Pain reduction after pelvic/ laparoscopic interventions by insufflation of $\mathrm{CO} 2$ gas at body temperature Flow-Therme). Geburtshilfu Frauenheilkd 54: 301-4.

32. Kojima Y, Yokota S, Ina H (2004) Shoulder pain after gynaecological laparoscopy caused by arm abduction. Eur J Anaesth 21: 578-579.

33. Chamberlain $\mathrm{G}$ (1984) The recovery of gases insufflated at laparoscopy. $\mathrm{Br} J$ Obstet Gynaecol 91: 367-70.

34. Paolucci V, Gutt CN, Schaeff B, Encke A (1995) Gasless laparoscopy in abdominal surgery. Surg Endosc 9: 497-500.

35. Huang ML, Chao C, Mong FU Tsao MJ (2001) Intraperitoneal infusion of Normal Saline to reduce postoperative pain in patients receiving Laparoscopic Cholecystectomy - Experience in MTYH. J Med Sci 216: 273-276.

36. Kandil TS, Hefnawy EEL (2010) Shoulder pain following laparoscopic cholecystectomy: Factors affecting the incidence and severity. Journal of Laparoendoscopic and Advanced Surgical Techniques 20: 677-682.

37. Perry CP, Trombello R (1993) Effect of fluid instillation on postlaparoscopy pain J Reprod Med 38: 768-770.

38. Duchene $P$ (1994) Analgesia after laparoscopy of the intraperitoneal physiogical serum. Ann Fr Anesth Reanim 13: 435.

39. Tsai HW, Chen YJ, Ho CM, Hseu SS, Chao KC, et al. (2011) Maneuvers to decrease Laparoscopy-Induced Shoulder and Upper Abdominal Pain A Randomized Controlled Study. Arch Surg 146: 1360-66. 